\title{
Severely Regurgitant Left Ventricle to Ascending Aorta Conduit in a Failing Fontan \\ Patient Treated with a Vascular Endograft and Melody Transcatheter Pulmonary Valve via Hybrid Approach
}
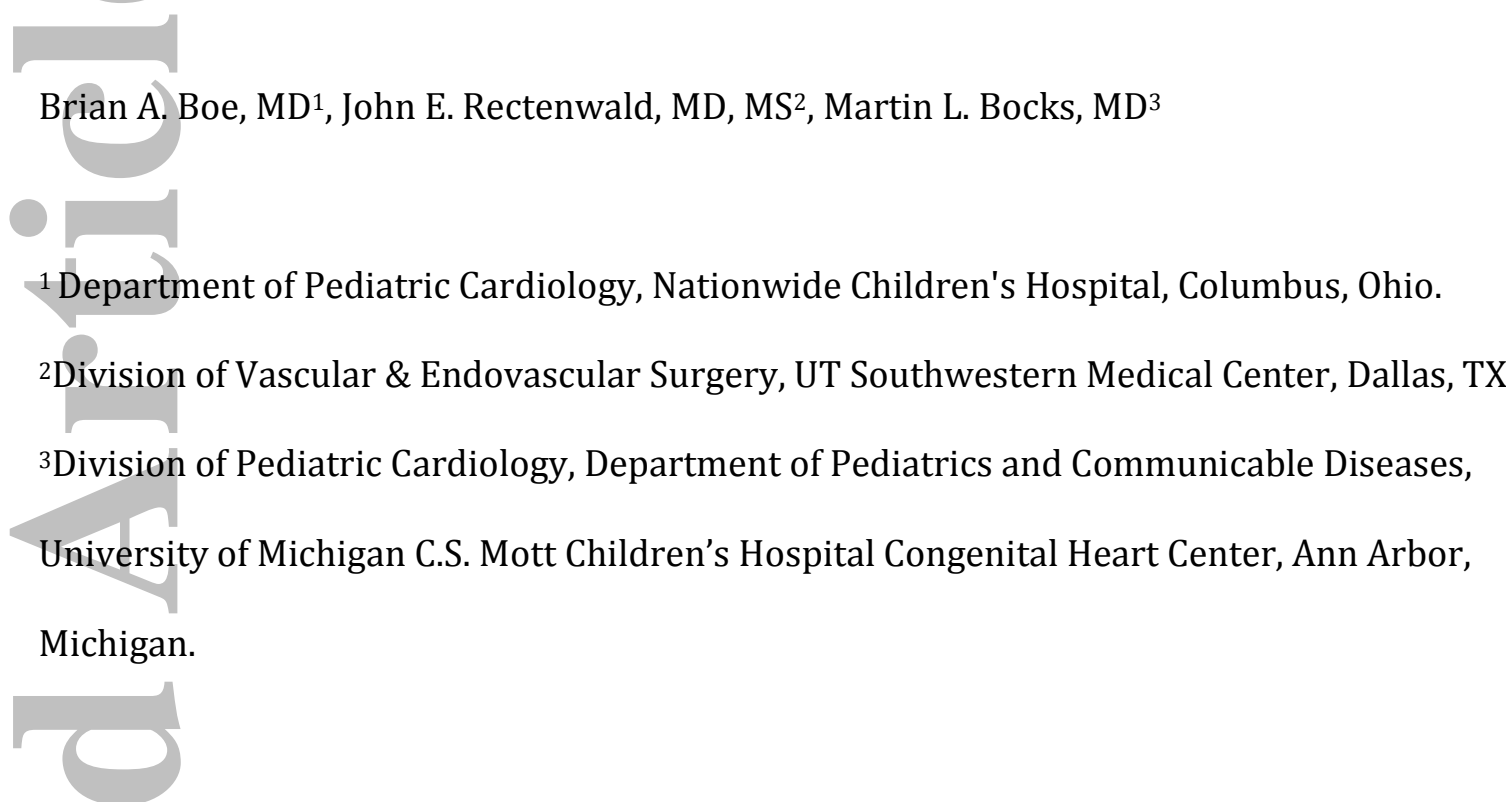

Keywords: Congenital catheterization, Intervention, Valve implantation

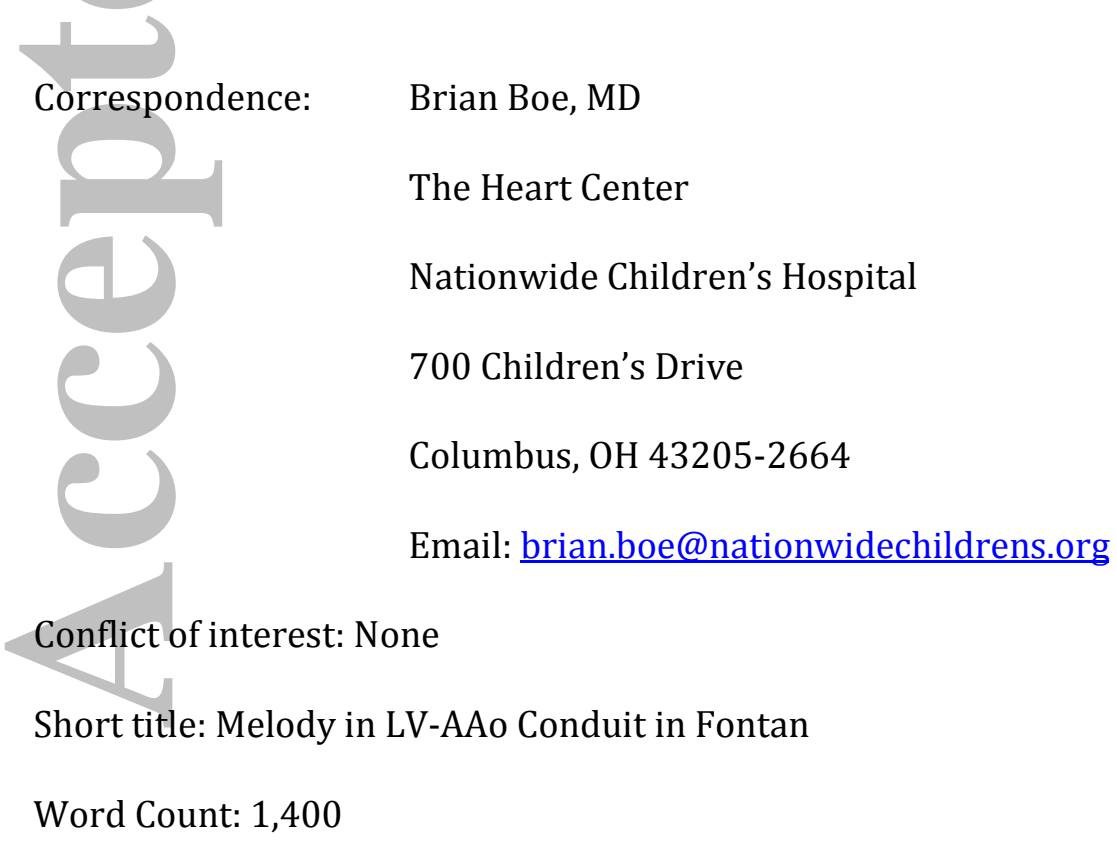

This is the author manuscript accepted for publication and has undergone full peer review but has not been through the copyediting, typesetting, pagination and proofreading process, which may lead to differences between this version and the Version record. Please cite this article as doi:10.1002/ ccd.26578. 


\section{ABSTRACT}

A 28 year-old male with single ventricular heart disease status post Fontan palliation and subsequent placement of left ventricle to ascending aorta (LV-AAo) valved conduit developed ascites and edema. Diagnostic catheterization revealed elevated ventricular end diastolic pressures (EDP) secondary to severe LV-AAo conduit regurgitation. Given the unique anatomy, surgical access via the right axillary artery provided optimal route for transcatheter valve implantation (TVI) within the conduit. The procedure resulted in significant hemodynamic improvement with no complications.

\section{INTRODUCTION}

Single ventricle patients with declining or failing Fontan circulations often have limited interventional options for improving overall hemodynamics and functional status $(1,2)$. The off-label use of FDA approved transcatheter valves provides a relatively new therapeutic option for patients with palliated complex congenital heart disease $(3,4)$. We describe the innovative use of transcatheter valve implantation (TVI) in a failing Fontan patient using a hybrid surgical vascular access approach.

\section{CASE HISTORY}

A 28 year-old male with d-transposition of the great arteries, hypoplastic right ventricle (RV), ventricular septal defect (VSD) and straddling tricuspid valve underwent pulmonary artery banding at one year of age followed by a classic Fontan with pulmonary artery ligation at age 2. Four years following his Fontan operation, the patient underwent placement of a $20 \mathrm{~mm}$ valved homograft conduit from the left ventricle to ascending aorta (LV-AAo) due to progressive severe restriction of the VSD and outflow to the aorta. At 22 years of age, he developed multiple atrial arrhythmias and underwent a revision of his 
Fontan with a $24 \mathrm{~mm}$ intra-atrial conduit, Maze procedure and placement of an epicardial pacemaker system. Preoperative catheterization prior to Fontan revision demonstrated no conduit regurgitation and minimal gradient (peak systolic ejection gradient $5 \mathrm{mmHg}$ ). As a result, the conduit was not replaced at that time. Six years following his Fontan revision, he developed symptoms of abdominal ascites and lower extremity edema. Given his new and progressive symptoms, the patient was referred to the catheterization laboratory. Hemodynamic evaluation revealed mean Fontan pressures of $25 \mathrm{mmHg}$ secondary to elevated RV and LV end diastolic pressures (EDP) of 22 and $21 \mathrm{mmHg}$, respectively. The peak systolic ejection gradient across the conduit was $10 \mathrm{mmHg}$ (Figure 1). The heavily and circumferentially calcified LV-AAo conduit had severe regurgitation (Figure 2). The patient was an extremely high-risk surgical candidate secondary to his numerous prior

sternotomies, high Fontan pressures, severe diastolic dysfunction, and calcified conduit with close proximity to the sternum. As a result he was referred back to the catheterization laboratory two months later for TVI within the LV-AAo conduit.

The LV-AAo conduit inserted on the leftward aspect of the ascending aorta following the lesser curve of the transverse arch. This created an almost 180 degree turn from the transverse arch to the distal insertion point of the LV-AAo conduit and precluded transcatheter valve delivery from a femoral arterial approach. In addition, the proximal LVAAo conduit takeoff was from the LV apex with an oblique orientation to the ventricle, which precluded transapical delivery approach. Vascular surgery was consulted to provide access via the right axillary artery. Consent for off-label use of a humanitarian device was obtained.

An $8 \mathrm{~mm}$ Dacron ${ }^{\circledR}$ graft was anastomosed at an oblique angle directly to the right axillary artery, which provided the most direct approach to the LV-AAo conduit via the right innominate artery (Figure 3). The distal end of the tube graft was clamped with a vascular 
clamp for hemostasis and the catheterization was performed via direct puncture through the anterior aspect of the Dacron ${ }^{\circledR}$ graft. Once the conduit was accessed, a $20 \mathrm{~mm}$ x $82 \mathrm{~mm}$ Endurant II ${ }^{\mathrm{TM}}$ stent graft (Medtronic, Minneapolis, MN) was inserted using the 16 French Sentrant sheath (Medtronic, Minneapolis, MN). The stent graft was placed within the heavily calcified LV-AAo conduit prior to angioplasty to protect from potential catastrophic rupture secondary to its position within the high pressure systemic circulation. The stent graft also prevented potential calcific embolization/stroke as a result of anticipated aggressive conduit dilation. The calcified conduit created a very rigid tube which measured $18-20 \mathrm{~mm}$ along the entire course with little to no pulsatility. Therefore, we did not feel additional presenting was necessary and proceeded directly to TVI. A Melody Transcatheter Pulmonary Valve ${ }^{\circledR}$ (TPV) (Medtronic, Minneapolis, MN) was implanted within the LV-AAo conduit on a 20-mm Ensemble ${ }^{\circledR}$ Transcatheter Valve Delivery System (Medtronic, Minneapolis, MN) entirely within the distal end of the stent graft. Due to the significant residual narrowing within the Melody TPV following delivery, the entire length of the stent graft and Melody valve was dilated using a $20 \mathrm{~mm}$ x $2 \mathrm{~cm}$ Atlas Gold balloon (BARD Peripheral Vascular, Tempe, AZ) with effective relief of the stent narrowing (Figure 4). Postprocedural LV EDP dropped considerably to $10 \mathrm{mmHg}$ and the LV-AAo conduit peak systolic ejection gradient was unchanged at $11 \mathrm{mmHg}$. Angiography demonstrated no residual LVAAo conduit insufficiency and no perivalvar leak (Figure 5). The axillary artery access site was repaired and wound site closed. The patient tolerated the procedure well without complication and was discharged to home the following day.

\section{DISCUSSION}

We report the use of a transcatheter valve to treat a failing Fontan patient secondary to LV-AAo conduit insufficiency via a hybrid surgical approach. There are few publications 
describing transcatheter valve placement within the systemic semilunar valve position in patients with complex congenital heart disease (5-7). The approaches reported include hybrid transapical, cutdown on the innominate artery, and percutaneously via femoral or internal jugular veins. Given the patient's unique anatomy, a hybrid surgical approach via a vascular graft provided an ideal approach for intervention in our patient. This approach has been utilized in adult patients to facilitate the implantation of transcatheter aortic valves and catheter-based Impella ${ }^{\circledR}$ left ventricular assist devices (ABIOMED, Inc. Danvers, MA) $(8,9)$. In addition to limiting the injury of the axillary artery, the tube graft provided additional vascular length for manipulation of the $100 \mathrm{~cm}$ long delivery system.

The Melody TPV is made from a bovine jugular venous valve which has naturally deep commissures allowing for competency in non-circular outflow tracts. The valve is supported by a platinum/iridium frame which is highly malleable and can conform to irregular conduits (10). We were uncertain of the final configuration and long-term diameter of the heavily calcified LV-AAo conduit in this patient and felt the Melody TPV would function better than a Sapien Valve (Edwards Lifesciences Corporation, Irvine, CA) in a possible elliptical configuration and in a generally smaller outflow diameter. Conduit tear is a known risk for TVI and was the most common serious adverse event reported in the one-year follow-up of the Melody TPV multicenter Post-Approval Study (11). Heavily calcified conduits are at risk for rupture and have been successfully treated with covered stents such as the covered Cheatham Platinum stent (NuMED Inc., Hopkinton, NY) (11-13). The calcium deposits within the LV-AAo conduit circumscribed its entire length and would have extended beyond a single covered stent. Deployment of the stent graft within the patient's conduit prior to any intervention mitigated the bleeding risks from conduit rupture in the high pressure systemic circulation and protected against possible calcific embolization from the heavily calcified conduit. The stent graft was not used for typical 
Melody "pre-stenting" as is standardly performed in RV-PA conduits. The conduit stenosis provided an optimal landing zone for the transcatheter valve remote from the coronary arteries. The hybrid procedural approach coupled with the off-label use of the aortic stent graft and Melody TPV resulted in successful and uncomplicated treatment in this high-risk surgical patient.

Although the Melody TPV has performed well relatively high pressure circulations, the long term durability is not known and remains a concern in these off-label uses $(5,14)$. With the development of smaller diameter and more easily steerable transcatheter delivery systems, future re-intervention from the percutaneous femoral arterial approach may be possible. However in the absence of this technology, a similar well-planned hybrid approach remains a viable option for TVI in patients with complex congenital heart disease.

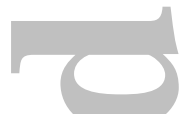

\section{CONCLUSION}

Innovative off-label use of transcatheter valve therapy can be used to treat high-risk patients, including failing Fontan patients that have limited medical and surgical options. Hybrid surgical approaches should be considered to provide the safest and most direct routes for TVI.

\section{ACKNOWLEDGEMENTS}

Thank you to Dr. Aimee Armstrong for her expertise in the planning and execution of this complicated case. We would also like to thank Donna Wilkin and Patricia Ferrer Beals for their work with the figures in this report. 


\section{REFERENCES}

1. Kaulitz R, Ziemer G, Paul T, Peuster M, Bertram H, Hausdorf G. Fontan-type procedures: residual lesions and late interventions. Ann Thorac Surg 2002;74(3):778-85.

2. Van Dorn CS, Menon SC, Johnson JT, Day RW, Hoffman JL, Yetman AT. Lifetime cardiac reinterventions following the fontan procedure. Pediatr Cardiol 2015;36(2):329-34.

3. Roberts PA, Boudjemline Y, Cheatham JP, Eicken A, Ewert P, McElhinney DB, Hill SL, Berger F, Khan D, Schranz D and others. Percutaneous tricuspid valve replacement in congenital and acquired heart disease. J Am Coll Cardiol 2011;58(2):117-22.

4. Cullen MW, Cabalka AK, Alli 00, Pislaru SV, Sorajja P, Nkomo VT, Malouf JF, Cetta F, Hagler DJ, Rihal CS. Transvenous, antegrade Melody valve-in-valve implantation for bioprosthetic mitral and tricuspid valve dysfunction: a case series in children and adults. JACC Cardiovasc Interv 2013;6(6):598-605.

5. Hasan BS, McElhinney DB, Brown DW, Cheatham JP, Vincent JA, Hellenbrand WE, Jones TK, Zahn EM, Lock JE. Short-term performance of the transcatheter Melody valve in high-pressure hemodynamic environments in the pulmonary and systemic circulations. Circ Cardiovasc Interv 2011;4(6):615-20.

6. Martin MH, Gruber PJ, Gray RG. Transcatheter neoaortic valve replacement utilizing the melody valve in hypoplastic left heart syndrome. Catheter Cardiovasc Interv 2015;85(4):615-9.

7. Gossl M, Johnson JN, Hagler DJ. Failing left ventricle to ascending aorta conduit-Hybrid implantation of a melody valve and NuMed covered stent. Catheter Cardiovasc Interv 2014;83(5):778-81.

8. Biasco L, De Backer O, Holme S, Sondergaard L, Jonsson A. The "Chimney approach" for transcatheter aortic valve implantation: A strategy for trans axillarian bareback approach in patients with no other access options.

Catheter Cardiovasc Interv 2015;86(3):E167-73.

9. Schibilsky D, Lausberg H, Haller C, Lenglinger M, Woernle B, Haeberle H, Rosenberger P, Walker T, Schlensak C. Impella 5.0 Support in INTERMACS II Cardiogenic Shock Patients Using Right and Left Axillary Artery Access. Artif Organs 2015;39(8):660-3.

10. McElhinney DB, Hennesen JT. The Melody(R) valve and Ensemble(R) delivery system for transcatheter pulmonary valve replacement. Ann N Y Acad Sci 2013;1291:77-85.

11. Armstrong AK, Balzer DT, Cabalka AK, Gray RG, Javois AJ, Moore JW, Rome JJ, Turner DR, Zellers TM, Kreutzer J. One-year follow-up of the melody transcatheter pulmonary valve multicenter post-approval study. JACC Cardiovasc Interv 2014;7(11):1254-62.

12. Boudjemline Y, Malekzadeh-Milani S, Patel M, Thambo JB, Bonnet D, Iserin L, Fraisse A. Predictors and outcomes of right ventricular outflow tract conduit rupture during percutaneous pulmonary valve implantation: a multicentre study. EuroIntervention 2014. 
13. Bishnoi RN, Jones TK, Kreutzer J, Ringel RE. NuMED covered cheathamplatinum stent for the treatment or prevention of right ventricular outflow tract conduit disruption during transcatheter pulmonary valve replacement. Catheter Cardiovasc Interv 2015;85(3):421-7.

14. Cheatham JP, Hellenbrand WE, Zahn EM, Jones TK, Berman DP, Vincent JA, McElhinney DB. Clinical and Hemodynamic Outcomes up to 7 Years After Transcatheter Pulmonary Valve Replacement in the US Melody Valve Investigational Device Exemption Trial. Circulation 2015;131(22):1960-70.
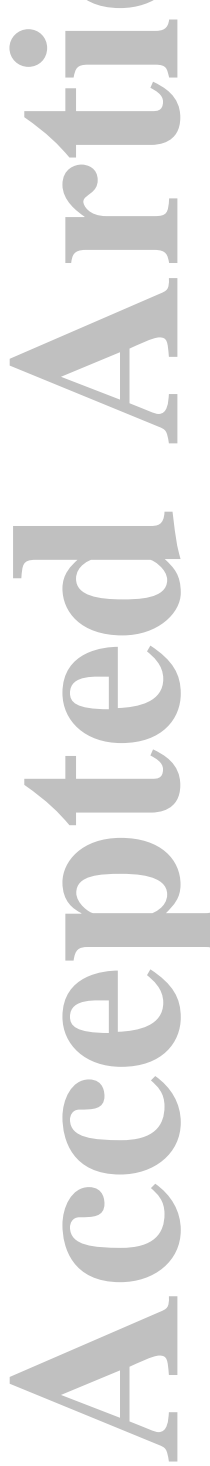


\section{LEGENDS}

Figure 1: Illustrative diagram depicting the patient's anatomy and hemodynamic measurements obtained during diagnostic catheterization. Ventricular pressures are noted as systolic/end diastolic pressure. $\mathrm{m}=$ mean pressure, $\mathrm{w}=$ mean wedge pressure.

Figure 2: The anteroposterior (A) and lateral (B) projections of an aortic root angiogram showing severe regurgitation of the calcified LV-AAo conduit.

Figure 3: Artistic illustration depicting the hybrid surgical approach used to obtain procedural access. The proximal Dacron ${ }^{\circledR}$ tube graft is sutured at an oblique angle to the axillary artery to facilitate procedural access. The distal Dacron ${ }^{\circledR}$ tube graft was clamped and the anterior aspect of the graft was directly punctured for the catheterization.

Figure 4: Intraprocedural images showing the delivery of the Melody TPV® within the Endurant II ${ }^{\mathrm{TM}}$ stent graft (A), balloon dilation of the Melody valve (B) and proximal Endurant II ${ }^{\mathrm{TM}}$ stent graft (C) with a $20 \mathrm{~mm}$ balloon. The Endurant II ${ }^{\mathrm{TM}}$ stent graft is noted by the black arrows and Melody TPV® is noted by the white arrowheads.

Figure 5: Final angiogram of the aortic root demonstrating no valvar regurgitation or perivalvar leak.

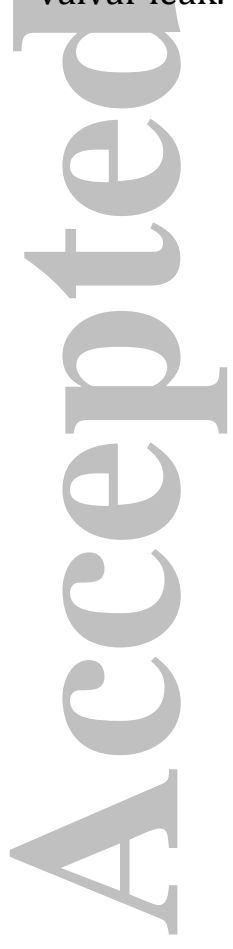




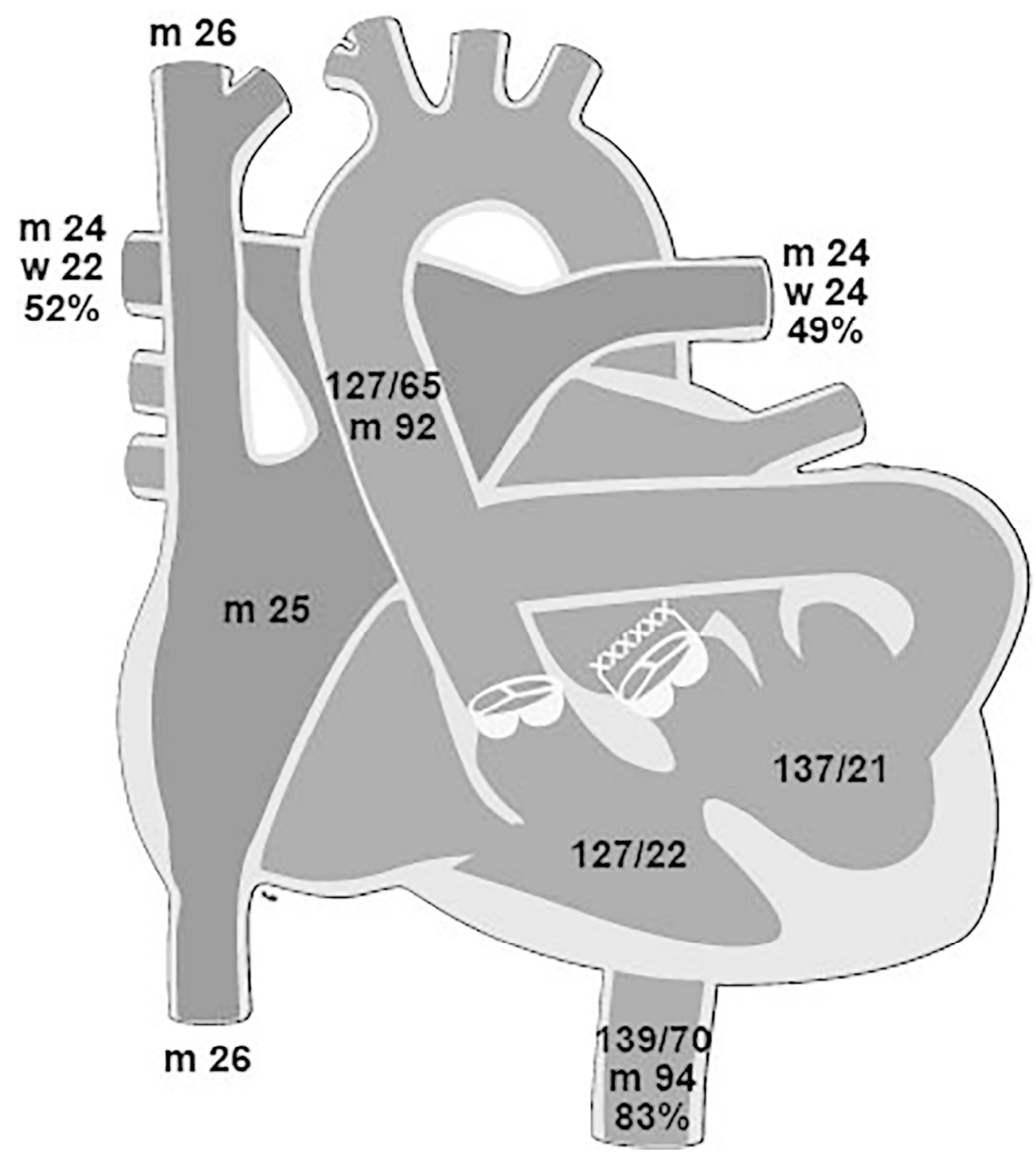

Figure 1: Illustrative diagram depicting the patient's anatomy and hemodynamic measurements obtained during diagnostic catheterization. Ventricular pressures are noted as systolic/end diastolic pressure. $\mathrm{m}=$ mean pressure, $\mathrm{w}=$ mean wedge pressure. $129 \times 145 \mathrm{~mm}(300 \times 300 \mathrm{DPI})$ 


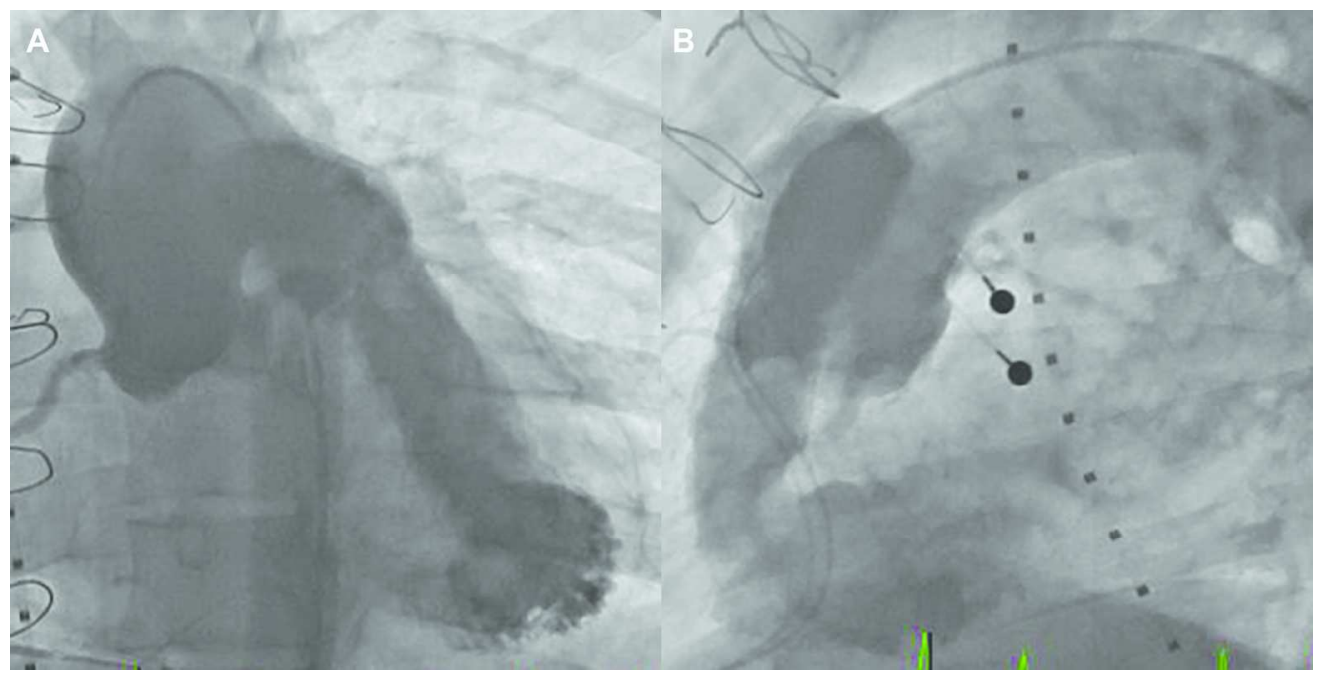

Figure 2: The anteroposterior (A) and lateral (B) projections of an aortic root angiogram showing severe regurgitation of the calcified LV-AAo conduit.

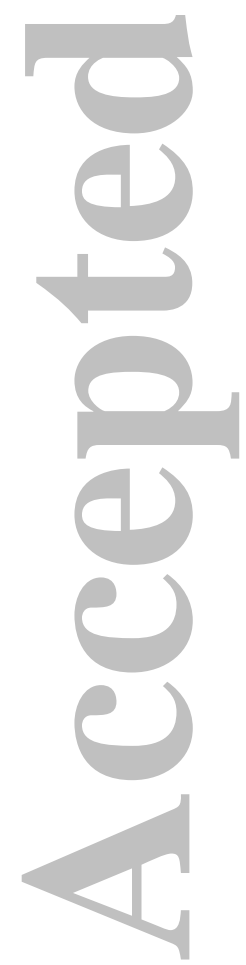
$250 \times 127 \mathrm{~mm}(300 \times 300 \mathrm{DPI})$ 


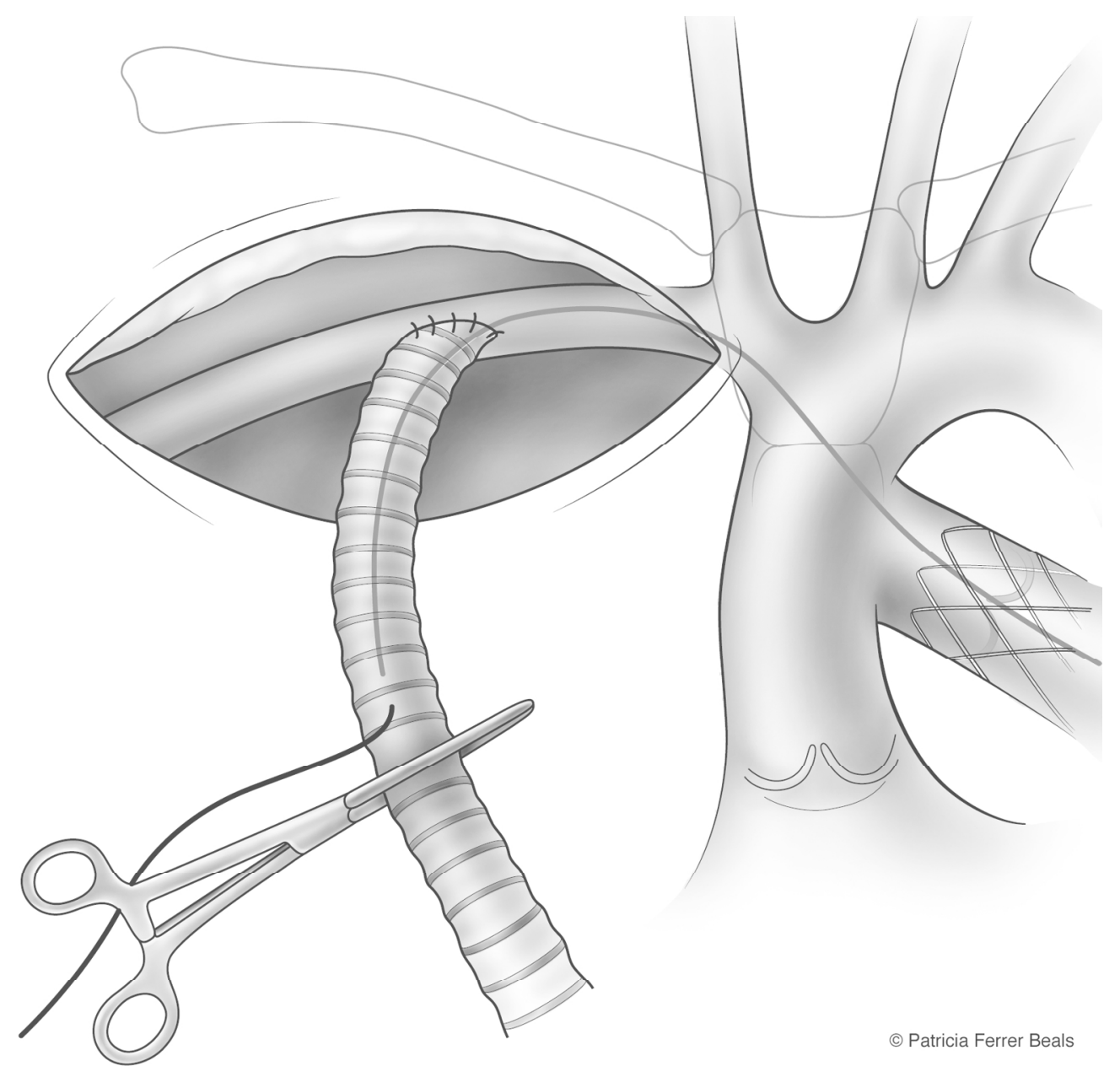

Figure 3: Artistic illustration depicting the hybrid surgical approach used to obtain procedural access. The proximal Dacron ${ }^{\circledR}$ tube graft is sutured at an oblique angle to the axillary artery to facilitate procedural access. The distal Dacron ${ }^{\circledR}$ tube graft was clamped and the anterior aspect of the graft was directly punctured for the catheterization.

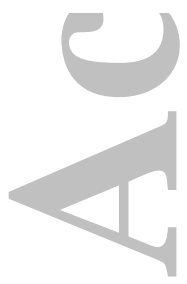
$148 \times 145 \mathrm{~mm}(300 \times 300 \mathrm{DPI})$ 


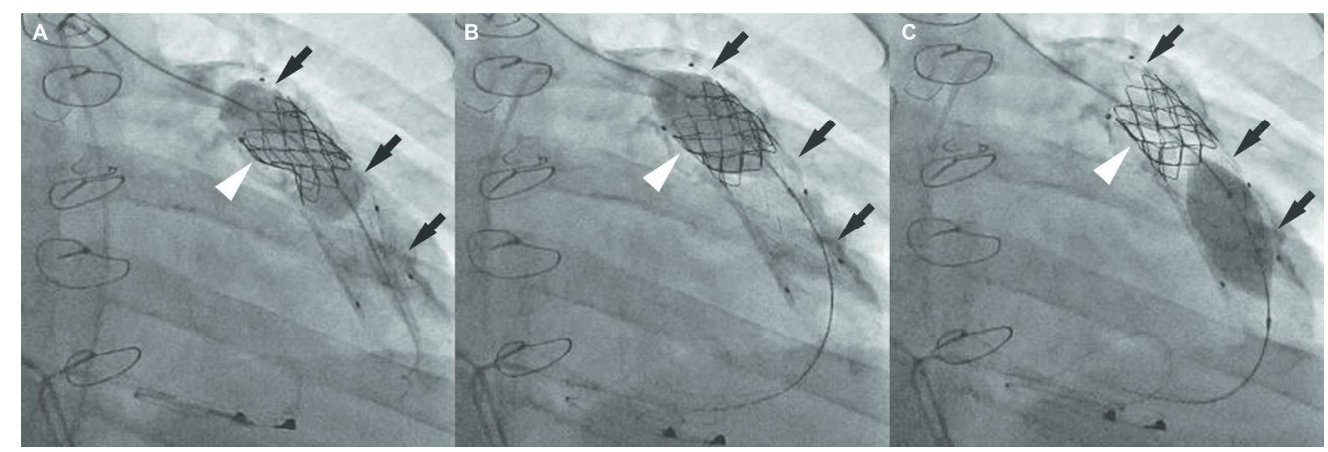

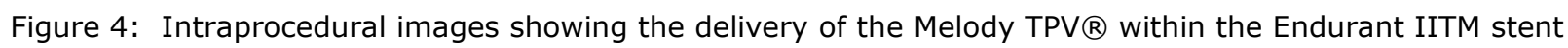
graft (A), balloon dilation of the Melody valve (B) and proximal Endurant IITM stent graft (C) with a $20 \mathrm{~mm}$

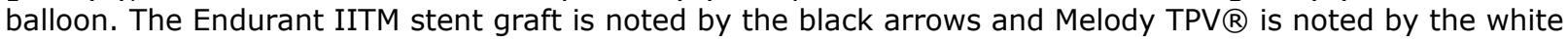
arrowheads.

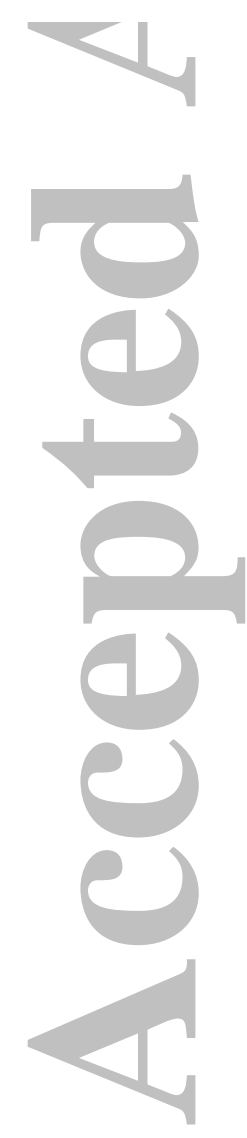

$381 \times 127 \mathrm{~mm}(300 \times 300 \mathrm{DPI})$ 


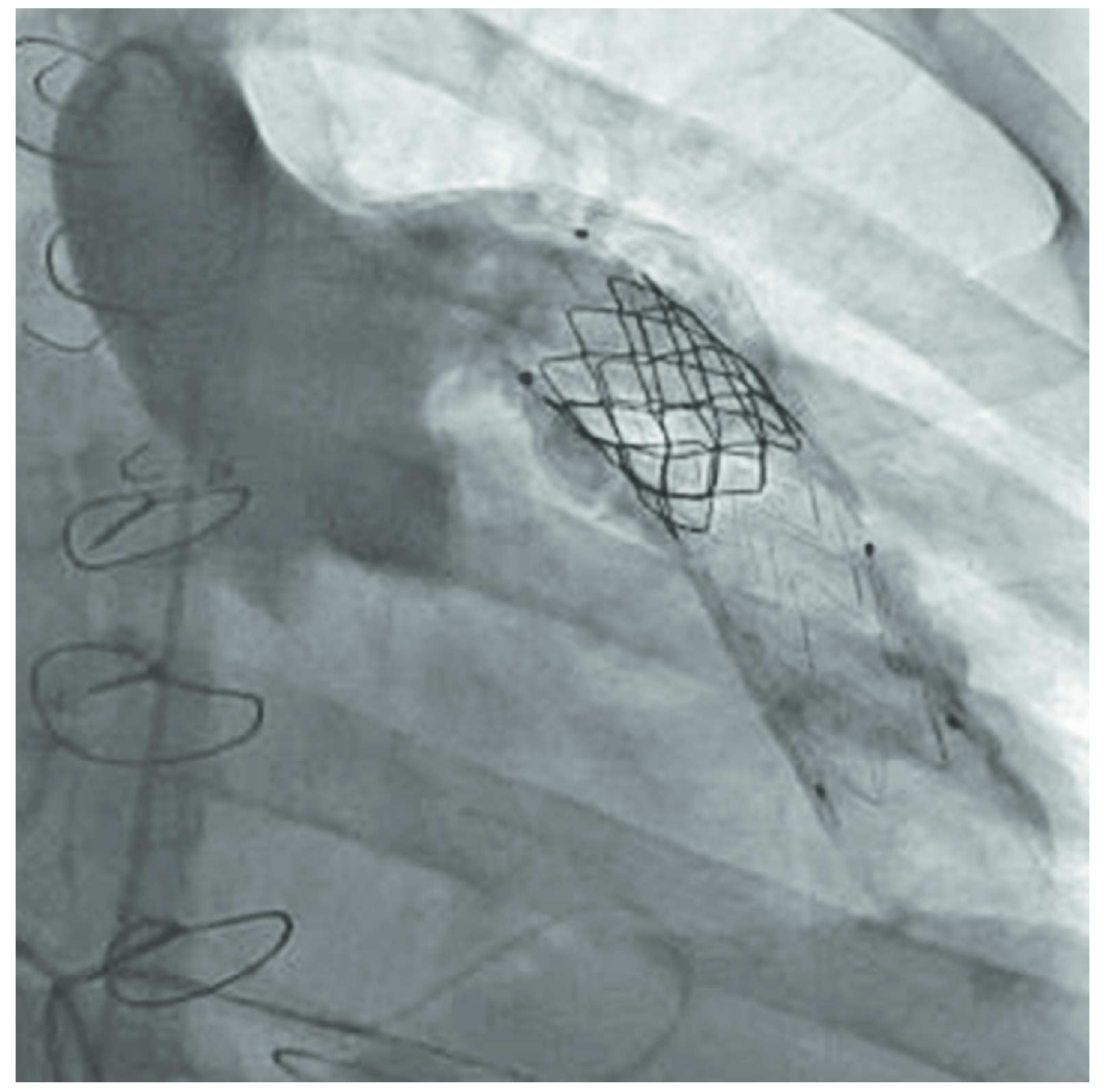

Figure 5: Final angiogram of the aortic root demonstrating no valvar regurgitation or peri-valvar leak.

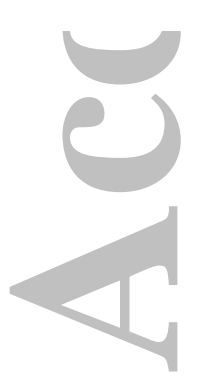
$130 \times 130 \mathrm{~mm}(300 \times 300 \mathrm{DPI})$ 


\section{Severely Regurgitant Left Ventricle to Ascending Aorta Conduit in a Failing Fontan}

Patient Treated with a Vascular Endograft and Melody Transcatheter Pulmonary Pative via

Valve via Novel-Hybrid Approach

$\Delta_{-}$

Brian A. Boe, MD¹, John E. Rectenwald, MD, MS², Martin L. Bocks, $\mathrm{MD}^{3}$

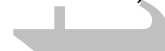

1 Department of Pediatric Cardiology, Nationwide Children's Hospital, Columbus, Ohio.

2Division of Vasscular \& Endovascular Surgery, UT Southwestern Medical Center, Dallas, TX.

3Division of Pediatric Cardiology, Department of Pediatrics and Communicable Diseases, University of Michigan C.S. Mott Children's Hospital Congenital Heart Center, Ann Arbor,

\section{Michigan.}

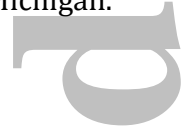

Keywords: Congenital catheterization, Intervention, Valve implantation

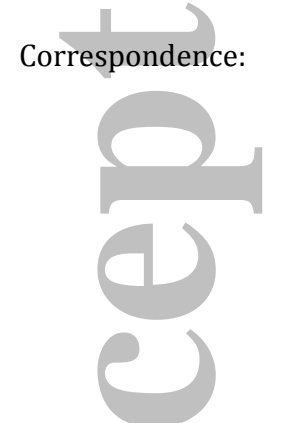

Brian Boe, MD

The Heart Center

Nationwide Children's Hospital

700 Children's Drive

Columbus, OH 43205-2664

Email: brian.boe@nationwidechildrens.org

Conflict of interest: None

Short title: Melody in LV-AAo Conduit in Fontan

Word Count: 1,105 $\underline{400}$

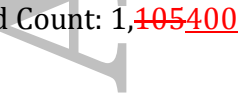

Formatted: Line spacing: Double 


\section{ABSTRACT}

A 28 year-old male with single ventricular heart disease status post Fontan palliation and subsequent placement of left ventricle to ascending aorta (LV-AAo) valved conduit placementdeveloped ascites and edema. Diagnostic catheterization revealed elevated ventricular end diastolic pressures (EDP) secondary to severe LV-AAo conduit (1)

regurgitation. Given the unique anatomy, surgical access via the right axillary artery provided optimal route for transcatheter valve implantation (TVI) within the conduit. The procedure resulted in significant hemodynamic improvement with no complications.

\section{INTRODUCTION}

Single ventricle patients with declining or failing Fontan circulations often have limited interventional options for improving overall hemodynamics and functional status $(1,2)$. The off-label use of FDA approved transcatheter valves provides a relatively new a therapeutic option for patients with palliated complex congenital heart disease $(3,4)$. We describe the innovative use of transcatheter valve implantation (TVI) in a failing Fontan patient using a novelhybrid surgical vascular access approach.

\section{CASE HISTORY}

A 28 year-old male with d-transposition of the great arteries, hypoplastic right ventricle (RV), ventricular septal defect (VSD) and straddling tricuspid valve underwent pulmonary artery banding at one year of age followed by a classic Fontan with pulmonary artery ligation at age 2.- Four years following his Fontan operation, the patient underwent placement of a $20 \mathrm{~mm}$ valved homograft conduit from the left ventricle to ascending aorta (LV-AAo) due to progressive severe restriction of the VSD and outflow to the aorta. At 22 years of age, he developed multiple atrial arrhythmias and underwent a revision of his 
Fontan with a $24 \mathrm{~mm}$ intra-atrial conduit, Maze procedure and placement of an epicardial pacemaker system. Preoperative catheterization prior to Fontan revision demonstrated no $\underline{\text { conduit regurgitation and minimal gradient (peak systolic ejection gradient } 5 \mathrm{mmHg} \text { ). As a }}$

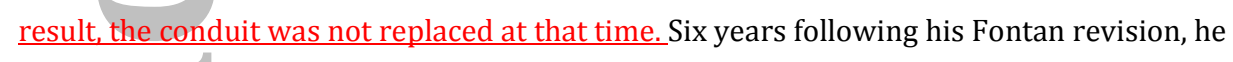
developed symptoms of abdominal ascites and lower extremity edema. Given his new and progressive symptoms, the patient was referred to the catheterization laboratory where hemodynamic. Hemodynamic evaluation revealed mean Fontan pressures of $25 \mathrm{mmHg}$ secondary to elevated RV and LV end diastolic pressures (EDP) of 22 and $21 \mathrm{mmHg}$, respectively. The peak systolic ejection gradient across the conduit was $10 \mathrm{mmHg}$ (Figure 1). The heavily and circumferentially calcified LV-AAo conduit had severe regurgitation

(Figure 2). As the The patient was an extremely high-risk surgical candidate secondary to his numerous prior sternotomies, high Fontan pressures, and-severe diastolic dysfunction, and calcified conduit with close proximity to the sternum. As a result he was referred back to the catheterization laboratory two months later for TVI within the LV-AAo conduit.

(The

The LV-AAo conduit inserted on the leftward aspect of the ascending aorta following the lesser curve of the transverse arch. This created an almost 180 degree turn from the transverse arch to the distal insertion point of the LV-AAo conduit and precluded transcatheter valve delivery from a femoral arterial approach. In addition, the proximal LVAAo conduit takeoff was from the LV apex with an oblique orientation to the ventricle, which precluded transapical transcatheter delivery approach. Vascular surgery was consulted to provide access via the right axillary artery. Consent for off-label use of a humanitarian device was obtained.

An $8 \mathrm{~mm}$ Dacron ${ }^{\circledR}$ tube graft was anastomosed at an oblique angle directly to the right axillary artery, which provided the most direct approach to the LV-AAo conduit via the right innominate artery (Figure 3). The distal end of the tube graft was clamped with a 
vascular clamp for hemostasis and the catheterization was performed via direct puncture through the anterior aspect of the Dacron ${ }^{\circledR}$ graft. Once the conduit was accessed, a $20 \mathrm{~mm}$ x $82 \mathrm{~mm}$ Endurant II ${ }^{\mathrm{TM}}$ stent graft (Medtronic, Minneapolis, MN) was inserted using the 16 French Sentrant sheath (Medtronic, Minneapolis, MN). The stent graft was placed within the heavily calcified LV-AAo conduit prior to angioplasty to protect from potential catastrophic rupture of the conduit.secondary to its position within the high pressure systemic $\underline{\text { circulation. The stent graft also prevented potential calcific embolization/stroke as a result }}$ of anticipated aggressive conduit dilation. The calcified conduit created a very rigid tube which measured 18-20 mm along the entire course with little to no pulsatility. Therefore, we did not feel additional presenting was necessary and proceeded directly to TVI. A

Melody Transcatheter Pulmonary Valve ${ }^{\circledR}$ (TPV) (Medtronic, Minneapolis, MN) was implanted within the LV-AAo conduit on a 20-mm Ensemble ${ }^{\circledR}$ Transcatheter Valve Delivery System (Medtronic, Minneapolis, MN) entirely within the distal end of the stent graft. There (Medtron wasDue to the significant residual narrowing within the Melody TPV stent afterfollowing delivery, so-the entire length of the stent graft and Melody valve was balloon-dilated withusing a $20 \mathrm{~mm} \times 2 \mathrm{~cm}$ Atlas Gold balloon (BARD Peripheral Vascular, Tempe, AZ) with effective relief of the stent narrowing (Figure 4). Post-procedural LV EDP dropped considerably to $10 \mathrm{mmHg}$ and the LV-AAo conduit peak systolic ejection gradient was unchanged at $11 \mathrm{mmHg}$. Angiography demonstrated no residual LV-AAo conduit insufficiency and no perivalvar leak (Figure 5). The axillary artery access site was repaired and wound site closed. The patient tolerated the procedure well without complication and was discharged to home the following day.

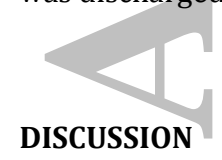




\begin{abstract}
We report the-first use of a transcatheter valve to treat a failing Fontan patient secondary to LV-AAo conduit insufficiency via a hybrid surgical approach. There are few publications describing transcatheter valve placement within the systemic semilunar valve position in patients with complex congenital heart disease (5-7). The approaches reported include percutaneous, hybrid transapical and ${ }_{2}$ cutdown on the innominate artery. Though ${ }_{2}$ and percutaneously via femoral or internal jugular veins. Given the patient's unique

anatomy precluded ${ }_{2}$ a previously described route of transcatheter valve delivery, the innominate arteryhybrid surgical approach via a vascular graft provided an ideal approach for intervention in our patient. This approach has been utilized in adult patients to facilitate $\underline{\text { the implantation of transcatheter aortic valves and catheter-based Impella } ® \text { left ventricular }}$ assist devices (ABIOMED, Inc. Danvers, MA) $(8,9)$. In addition to limiting the injury of the axillary artery, the tube graft provided additional vascular length for manipulation of the $100 \mathrm{~cm}$ long delivery system.

The Melody TPV is made from a bovine jugular venous valve which has naturally deep commissures allowing for competency in non-circular outflow tracts. The valve is supported by a platinum/iridium frame which is highly malleable and can conform to irregular conduits (10). We were uncertain of the final configuration and long-term diameter of the heavily calcified LV-AAo conduit in this patient and felt the Melody TPV would function better than a Sapien Valve (Edwards Lifesciences Corporation, Irvine, CA) in a possible elliptical configuration and in a generally smaller outflow diameter. Conduit tear is a known risk for TVI and was the most common serious adverse event reported in the one-year follow-up of the Melody TPV multicenter Post-Approval Study (8)(11). Heavily calcified conduits are at risk for rupture and have been successfully treated with covered stents such as the covered Cheatham Platinum stent (NuMED Inc., Hopkinton, NY) (810)(11-13):- The calcium deposits within the LV-AAo conduit circumscribed its entire length
\end{abstract}


and would have extended beyond a single covered stent. Deployment of the stent graft

within ourthe patient's conduit prior to Melody TPV implantationany intervention

mitigated the bleeding risks from conduit rupture in the high pressure systemic circulation

and protected against possible calcific embolization from the heavily calcified conduit. The

stent graft was not used for typical Melody "pre-stenting" as is standardly performed in RVPA

PA conduits. The conduit stenosis provided an optimal landing zone for the transcatheter

valve remote from the coronary arteries. Our novelThe hybrid procedural approach coupled with the off-label use of the aortic stent graft and Melody TPV resulted in successful and uncomplicated treatment in this high-risk surgical patient.

Although the Melody TPV has performed well relatively high pressure circulations, the long term durability is not known and remains a concern in these off-label uses $(5,11 \underline{14})$. With the development of smaller diameter and more easily steerable transcatheter delivery systems, future re-intervention from the percutaneous femoral (approach arterial approach may be possible. However in the absence of this technology, a similar .

well-planned hybrid approach as described-remains a viable option for TVI in patients with complex congenital heart anatomydisease.

\section{CONCLUSION}

Innovative off-label use of transcatheter valve therapy can be used to treat high-risk patients, including failing Fontan patients that have limited medical and surgical options. Novel hybridHybrid surgical approaches should be considered to provide the safest and most direct routes for TVI.

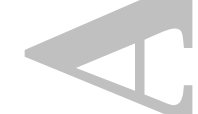

\section{ACKNOWLEDGEMENTS}




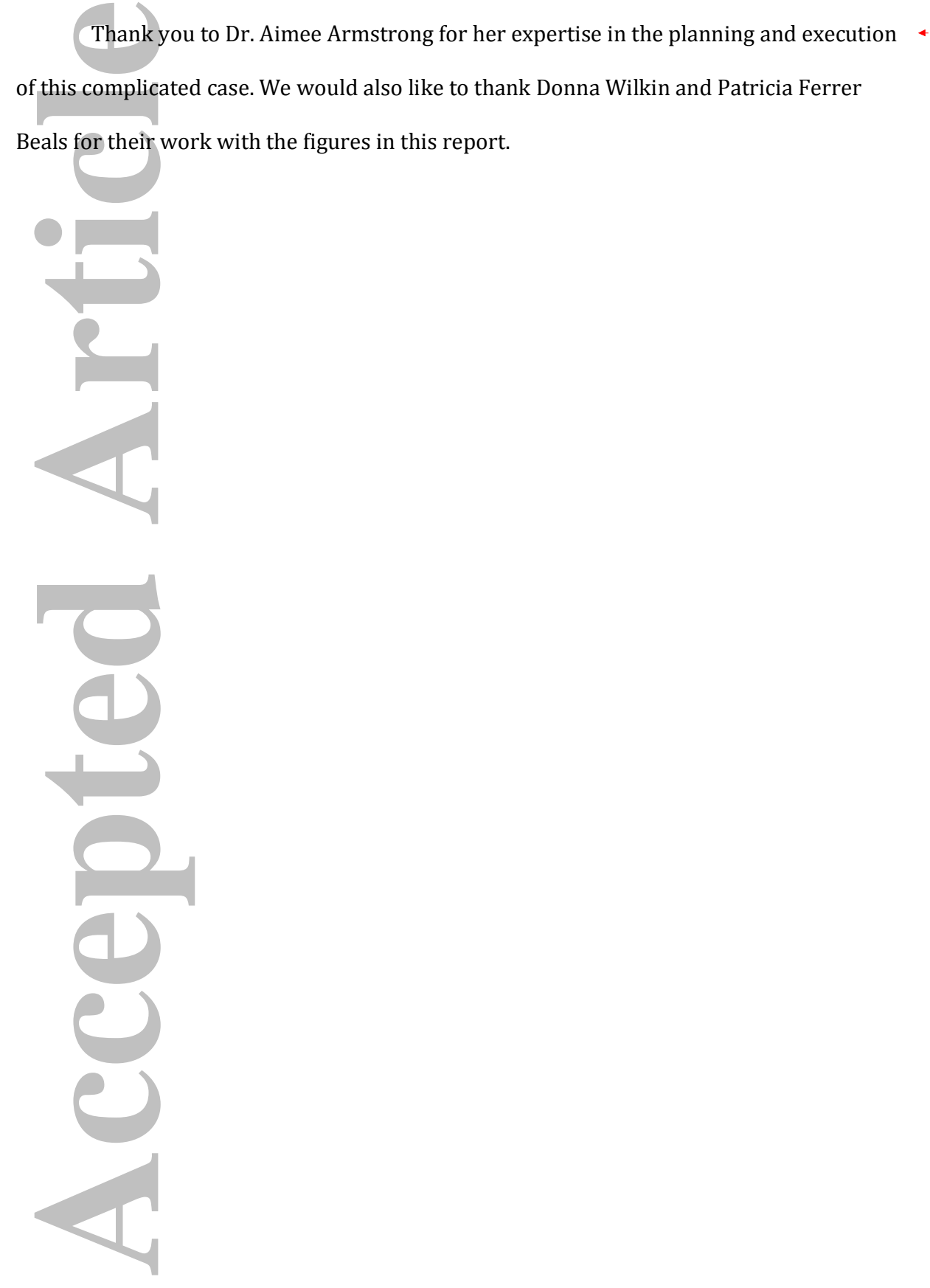




\section{REFERENCES}

1. Kaulitz R, Ziemer G, Paul T, Peuster M, Bertram H, Hausdorf G. Fontan-type procedures: residual lesions and late interventions. Ann Thorac Surg 2002;74(3):778-85.

2. Van Dorn CS, Menon SC, Johnson JT, Day RW, Hoffman JL, Yetman AT. Lifetime cardiac reinterventions following the fontan procedure. Pediatr Cardiol 2015;36(2):329-34.

3. Roberts PA, Boudjemline Y, Cheatham JP, Eicken A, Ewert P, McElhinney DB, Hill SL, Berger F, Khan D, Schranz D and others. Percutaneous tricuspid valve replacement in congenital and acquired heart disease. J Am Coll Cardiol 2011;58(2):117-22.

4. Cullen MW, Cabalka AK, Alli 00, Pislaru SV, Sorajja P, Nkomo VT, Malouf JF, Cetta F, Hagler DJ, Rihal CS. Transvenous, antegrade Melody valve-in-valve implantation for bioprosthetic mitral and tricuspid valve dysfunction: a case series in children and adults. JACC Cardiovasc Interv 2013;6(6):598-605.

5. Hasan BS, McElhinney DB, Brown DW, Cheatham JP, Vincent JA, Hellenbrand WE, Jones TK, Zahn EM, Lock JE. Short-term performance of the transcatheter Melody valve in high-pressure hemodynamic environments in the pulmonary and systemic circulations. Circ Cardiovasc Interv 2011;4(6):615-20.

6. Martin MH, Gruber PJ, Gray RG. Transcatheter neoaortic valve replacement utilizing the melody valve in hypoplastic left heart syndrome. Catheter Cardiovasc Interv 2015;85(4):615-9.

7. Gossl M, Johnson JN, Hagler DJ. Failing left ventricle to ascending aorta conduit-Hybrid implantation of a melody valve and NuMed covered stent.

Catheter Cardiovasc Interv 2014;83(5):778-81.

8. Biasco L, De Backer O, Holme S, Sondergaard L, Jonsson A. The "Chimney approach" for transcatheter aortic valve implantation: A strategy for trans axillarian bareback approach in patients with no other access options. Catheter Cardiovasc Interv 2015;86(3):E167-73.

9. Schibilsky D, Lausberg H, Haller C, Lenglinger M, Woernle B, Haeberle $H_{\text {, }}$ Rosenberger P, Walker T, Schlensak C. Impella 5.0 Support in INTERMACS II Cardiogenic Shock Patients Using Right and Left Axillary Artery Access. Artif Organs 2015;39(8):660-3.

10. McElhinney DB, Hennesen IT. The Melody(R) valve and Ensemble(R) delivery system for transcatheter pulmonary valve replacement. Ann N Y Acad Sci 2013;1291:77-85.

11. Armstrong AK, Balzer DT, Cabalka AK, Gray RG, Javois AJ, Moore JW, Rome JJ, * Turner DR, Zellers TM, Kreutzer J. One-year follow-up of the melody transcatheter pulmonary valve multicenter post-approval study. JACC Cardiovasc Interv 2014;7(11):1254-62.

912. Boudjemline Y, Malekzadeh-Milani S, Patel M, Thambo JB, Bonnet D, Iserin L, Fraisse A. Predictors and outcomes of right ventricular outflow tract conduit rupture during percutaneous pulmonary valve implantation: a multicentre study. EuroIntervention 2014.

Formatted: Font: Cambria, $12 \mathrm{pt}$

Formatted: Line spacing: single

Formatted: Font: Cambria, $12 \mathrm{pt}$ 


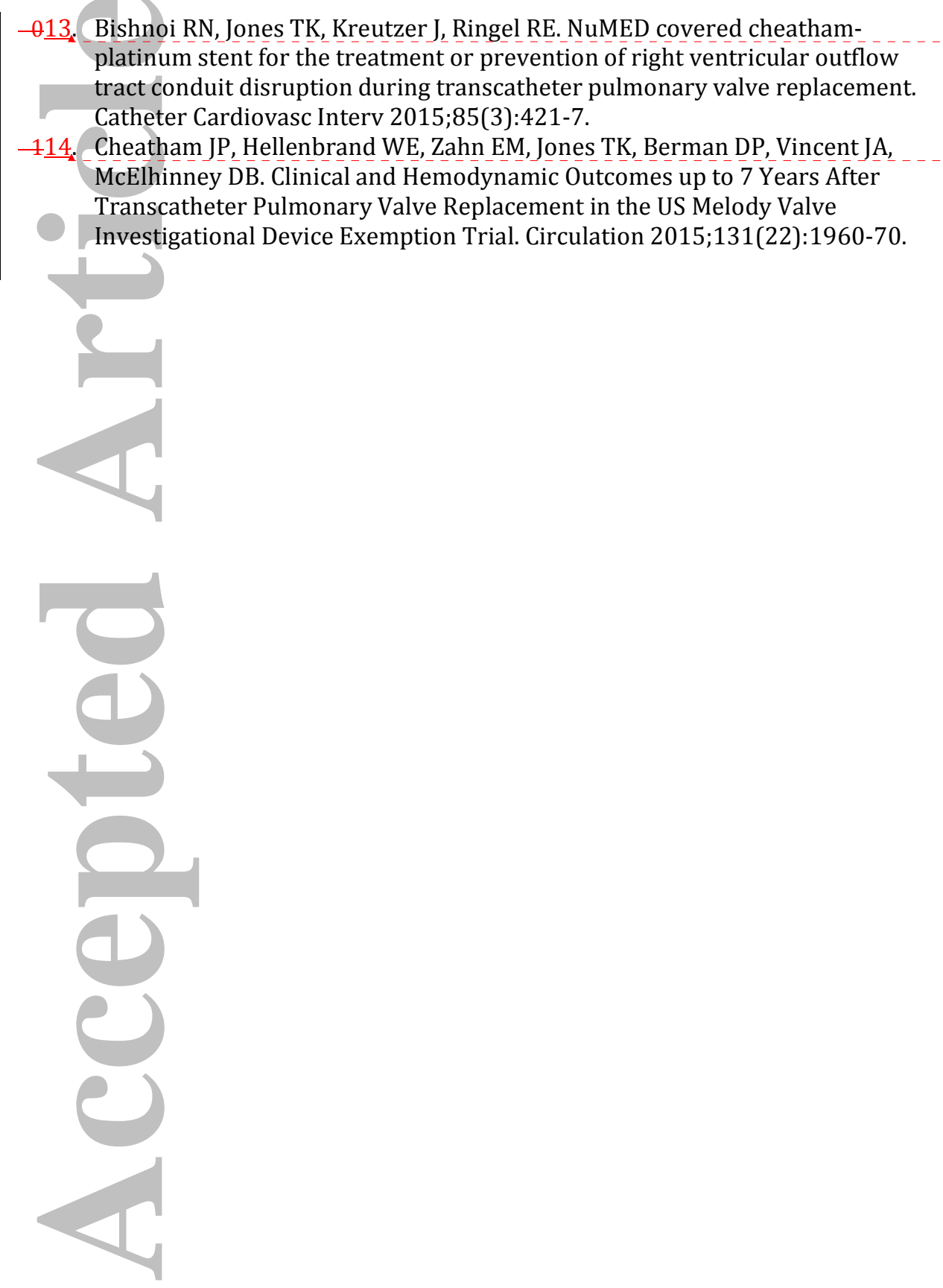

Formatted: Font: Cambria, $12 \mathrm{pt}$

Formatted: Font: Cambria, $12 \mathrm{pt}$ 


\section{LEGENDS}

Figure 1: Illustrative diagram depicting the patient's anatomy and hemodynamic measurements obtained during diagnostic catheterization. Ventricular pressures are noted as systolic/end diastolic pressure. $\mathrm{m}=$ mean pressure, $\mathrm{w}=$ mean wedge pressure.

Figure 2: The anteroposterior (A) and lateral (B) projections of an aortic root angiogram showing severe regurgitation of the calcified LV-AAo conduit.

$$
\text { (1) }
$$

Figure 3: Artistic illustration depicting the hybrid surgical approach used to obtain procedural access. The proximal Dacron ${ }^{\circledR}$ tube graft is sutured at an oblique angle to the axillary artery to facilitate procedural access. The distal Dacron ${ }^{\circledR}$ tube graft was clamped and the anterior aspect of the graft was directly punctured for the catheterization.

Figure 4: Intraprocedural images showing the delivery of the Melody TPV® within the Endurant IITM stent graft (A), balloon dilation of the Melody valve (B) and proximal Endurant IITM stent graft (C) with a $20 \mathrm{~mm}$ balloon. The Endurant IITM stent graft is noted by the black arrows and Melody TPV® is noted by the white arrowheads.

Figure 5: Final angiogram of the aortic root demonstrating no valvar regurgitation or perivalvar leak.

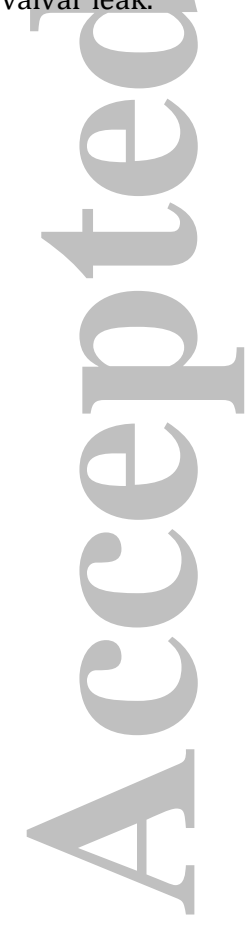

